\title{
Estudo da capacidade alcalinizante de tampões metabolizáveis em bovinos sadios
}

\author{
[The alkalinizing effects of different metabolizable buffers in healthy steers] \\ M.L.R. Leal ${ }^{1}$, C.S. Mori ${ }^{2}$, E.L. Ortolani ${ }^{2 *}$ \\ ${ }^{1}$ Universidade Federal de Santa Maria - Santa Maria, RS \\ ${ }^{2}$ Faculdade de Medicina Veterinária e Zootecnia - USP \\ Av. Prof. Orlando Marques de Paiva, 87 \\ 05508-900 - São Paulo, SP
}

\begin{abstract}
RESUMO
Seis novilhos mestiços, com cerca de $250 \mathrm{~kg}$ e um ano de idade, foram infundidos, no decorrer de quatro horas, com cinco litros de diferentes soluções isotônicas de sais sódicos, com $150 \mathrm{mM} / 1$ de bicarbonato, acetato, propionato, lactato L, lactato racêmico e cloreto (controle), em delineamento em quadrado latino (6x6). Análises hemogasométricas e do $\mathrm{pH}$ urinário foram determinadas no decorrer da infusão - zero, primeira e quatro horas - e após o seu término, na oitava hora. $\mathrm{O}$ pH do sangue foi maior nos animais infundidos com os tampões que nos infundidos com cloreto; teores mais elevados de bicarbonato e de excesso de ácido-base sanguíneos foram obtidos na quarta e oitava hora nos infundidos com bicarbonato e lactato; o mesmo ocorreu com a pressão de $\mathrm{CO}_{2}$ na oitava hora. Os resultados indicam que os tratamentos com Bicarbonato e lactato proporcionam acúmulo de tampões no sangue e geram discreta alcalose metabólica, compensada organicamente por leve retenção de $\mathrm{CO}_{2}$. a infusão com bicarbonato de sódio causa elevação do pH urinário.
\end{abstract}

Palavras-chave: bovino, tampão, tratamento, acidose metabólica, alcalinização

\begin{abstract}
Six healthy crossbred yearling $250 \mathrm{~kg}$ steers were infused intravenously, during four hours, with five liters of each of the six different isotonic solutions of sodium salts containing $150 \mathrm{mMol} / \mathrm{l}$ of the bicarbonate, acetate, propionate, L-lactate, $D$ and L-lactate and chloride in a $6 \times 6$ latin square experimental design. Blood was collected from the jugular vein, anaerobically, for blood gas analysis, samples were obtained at different times throughout the infusion (zero, $1^{\text {st }}, 4^{\text {th }}$ and $8^{\text {th }} \mathrm{h}$ ). Urine was collect for determining the $\mathrm{pH}$ at the same schedule. Higher blood $\mathrm{pH}$ was found in cattle infused with all buffers than the chloride infused animals; higher level of blood bicarbonate and base excess were obtained at $4^{\text {th }}$ and $8^{\text {th }} h$ with bicarbonate and L-lactate, as well as with $\mathrm{pCO}_{2}$ at the $8^{\text {th }} \mathrm{h}$. These results show that treatments with $\mathrm{B}$ and L lead to a slight accumulation of buffers in the blood, and generate a discrete metabolic alkalosis compensated organically by a small retention of $\mathrm{CO}_{2}$. Best alkalinizing effects are obtained by bicarbonate and L-lactato infusions. Bicarbonate infusions causes a high urinary $\mathrm{pH}$.
\end{abstract}

Keywords: cattle, buffer, treatment, metabolic acidosis, alkalinizing

\section{INTRODUÇ̃̃O}

Várias são as enfermidades em bovinos que provocam quadros de acidose metabólica sistêmica (AMS), caracterizada por diminuição tanto do $\mathrm{pH}$ como do teor de bicarbonato sangüíneo. Entre as enfermidades destacam-se: a acidose láctica ruminal, a intoxicação por uréia, as enterotoxemias, os quadros diarréicos e outros que levam à síndrome da desidratação (Dunlop, 1972; Maruta e Ortolani, 2002; Radostits et al., 2002).

O tratamento clássico da AMS é por meio de infusão de soluções de Bicarbonato. $\mathrm{O}$ uso excessivo desse tampão, contudo, por erro na

Recebido em 20 de dezembro de 2005

Aceito em 4 de maio de 2007

Autor para correspondência (corresponding author)

E-mail: ortolani@usp.br 


\section{Leal et al.}

avaliação do grau da acidose metabólica, pode trazer sérios inconvenientes aos ruminantes, tais como: alcalose sistêmica iatrogênica, intoxicação por sódio, hipocalemia, edema cerebral e acidose paradoxal do fluido cerebroespinhal (Hartsfield et al., 1981).

Uma alternativa para sobrepor esse problema seria a utilização de tampões metabolizáveis, tais como lactato $\mathrm{L}$, lactatos $\mathrm{D}$ e $\mathrm{L}$, acetato e propionato. Enquanto que o bicarbonato tem imediato efeito alcalinizante ao combinar-se diretamente com íons hidrogênio, os outros tampões citados precisam de ser metabolizados em órgãos específicos para que possam exercer sua capacidade alcalinizante, não incorrendo em risco de causar efeitos colaterais (Hartsfield et al., 1981). O emprego de tampões metabolizáveis foi bem estudado em bezerros neonatos normais e com diarréia (Naylor e Forsyth, 1986). Porém, bezerros lactentes podem ter nuances metabólicas diferentes de bovinos adultos (Armentano, 1992). Até o momento, nenhum estudo semelhante foi feito, nessa última categoria de animais.

O objetivo deste estudo foi avaliar a capacidade alcalinizante do bicarbonato e de alguns tampões metabolizáveis em bovinos hígidos, selecionando-se os melhores tampões para serem testados em um segundo experimento em bovinos adultos com acidose.

\section{MATERIAL E MÉTODOS}

Foram utilizados seis novilhos mestiços, sadios, com aproximadamente $250 \mathrm{~kg}$ e um ano de idade. Esses animais foram alimentados, previamente e no decorrer do experimento, com uma dieta com $80 \%$ da matéria seca de feno de capim-coast cross (Cynodon dactylon) e $20 \%$ de ração concentrada $(75 \%$ de farelo de trigo e $25 \%$ de farelo de soja), além de minerais e água à vontade.

Seguiu-se um delineamento em quadrado latino (6 tratamentos X 6 unidades experimentais), com um intervalo mínimo de 10 dias entre cada tratamento. Os animais foram infundidos com soluções isotônicas $(150 \mathrm{mM} / \mathrm{l})$ de cada tampão dissolvido em água bidestilada e autoclavada a $125^{\circ} \mathrm{C}$. As soluções foram feitas pela adição dos seguintes sais sódicos em água: bicarbonato (B), propionato $(\mathrm{P})$, lactato racêmico $(\mathrm{DL})$, lactato $\mathrm{L}$
(L), acetato (A) e cloreto (C). Este último representou o grupo-controle. Para tal, foram utilizadas, por litro de solução, as seguintes quantidades de sais sódicos: $\mathrm{B}$ - 12,60g; P 10,90g; DL e L-16,65g; A - 12,38g, C - 8,77g. A solução de DL foi composta por sais de lactato $50 \%$ dextrogiro e $50 \%$ levogiro. A velocidade de infusão foi de $20,8 \mathrm{ml} / \mathrm{min}$, no decorrer de quatro horas, perfazendo um total de 51 no período, semelhante ao protocolo descrito por Naylor e Forsyth (1986) em bezerros sadios. Antes do início da infusão foram implantados nos animais dois cateteres de polietileno ${ }^{1}$ nas veias jugulares esquerda e direita, sendo na primeira injetada a solução e na segunda destinada à coleta de sangue para análise.

Foram realizadas coletas de sangue e urina no tempo basal, primeira, quarta e oitava hora após o início da infusão de cada tampão. O sangue foi coletado, em condições anaeróbicas, com seringa com heparinato de sódio como anticoagulante, diretamente do cateter intravenoso. $\mathrm{O} \mathrm{pH}$, as concentrações de bicarbonato sangüíneo, o excesso de ácido base sangüíneos (EAB), que indica o grau de depleção ou acúmulo dos tampões no sangue, e a pressão de $\mathrm{CO}_{2}$ foram determinados em aparelho de hemogasometria ${ }^{2}$, seguindo recomendações sugeridas por Sucupira e Ortolani (2003). Amostras de urina foram coletadas por meio de massagem prepucial e imediatamente tiveram seu $\mathrm{pH}$ mensurado, em pHmetro digital ${ }^{3}$.

Como os resultados de todas as variáveis estudadas apresentavam no momento basal valores com coeficiente de variação relativamente alto, semelhante ao que foi encontrado por Naylor e Forsyth (1986) em bezerros sadios, padronizou-se que os valores individuais seriam considerados como zero, e a partir das infusões calculou-se a diferença, positiva ou negativa, destas. Os valores de todas as variáveis estudadas se encontravam dentro dos limites de normalidade no tempo basal (Ortolani, 2003).

O delineamento em quadrado latino teve seu arranjo em parcelas subdivididas, considerando os tampões utilizados como parcela e os tempos

${ }^{1} \mathrm{BD}$ - Intracath (1,7mm x 30,5mm) - Juiz de Fora, Brasil

${ }^{2} \mathrm{AVL}$ - São Paulo, SP

${ }^{3}$ DM-20 Digimed - São Paulo, Brasil 
de coleta como subparcelas. Os dados foram inicialmente submetidos à análise de variância e em seguida suas médias comparadas por diferença mínima significativa (DMS) utilizando t tabelado ponderado e fixando como nível de significância 5\% (Sampaio, 2002). O coeficiente de variação $\left(\mathrm{CV}_{\mathrm{b}}\right)$ também foi calculado relativo à instabilidade das subparcelas (Sampaio, 2002).

\section{RESULTADOS}

$\mathrm{Na}$ primeira, quarta e oitava horas o $\mathrm{pH}$ sangüíneo foi mais elevado em animais infundidos com todos os tampões que os infundidos com cloreto $(\mathrm{P}<0,05)$, exceto na oitava hora, em que o cloreto foi semelhante ao propionato (Fig. 1). $\mathrm{O} \mathrm{pH}$ obtido na primeira hora foi mais alto nos animais tratados com propionato que nos tratados com acetato e bicarbonato; já na oitava hora, o propionato foi mais baixo que todos os demais tampões $(\mathrm{P}<0,05)$. Dois dos cinco animais tratados com bicarbonato e lactato- $\mathrm{L}$ apresentaram valores de $\mathrm{pH}$ sangüíneo na quarta hora ligeiramente mais altos que 7,40 .

Dentro dos tratamentos, maiores valores de $\mathrm{pH}$ sangüíneo foram obtidos na quarta hora após a infusão com bicarbonato, ocorrendo tal fato na primeira hora com a aplicação de propionato $(\mathrm{P}>0,05) . \mathrm{O}_{\mathrm{b}}$ das amostras de $\mathrm{pH}$ sangüíneo foi de $10,7 \%$.

Os teores de bicarbonato e de EAB sangüíneos (Fig. 2 e 3) foram mais elevados na primeira hora nos animais tratados com bicarbonato $\mathrm{e}$ propionato que nos tratados dos demais grupos, ocorrendo o mesmo fato na quarta e oitava horas com o bicarbonato e lactato-L, exceto na oitava hora, em que o EAB foi maior em bovinos infundidos com bicarbonato $(\mathrm{P}<0,05)$. A bicarbonatemia foi mais baixa na primeira e oitava horas nos animais medicados com cloreto. A análise dentro de cada tratamento indicou que os teores de bicarbonato sangüíneos foram mais elevados na primeira e quarta horas após a infusão de propionato e lactato-L, respectivamente $(\mathrm{P}<0,05)$, e não houve diferença entre as demais soluções utilizadas. Em relação ao EAB obtiveram-se teores mais altos na quarta hora após o uso de lactato-L $(\mathrm{P}<0,05)$, e ocorreu diminuição na oitava hora em relação aos demais momentos no tratamento com propionato; nos outros tratamentos não foram detectadas diferenças. Os $\mathrm{CV}_{\mathrm{b}}$ do bicarbonato e do $\mathrm{EAB}$ foram $12,7 \%$ e $11,4 \%$, respectivamente.

Os valores médios de pressão de $\mathrm{CO}_{2}$ (Fig. 4) sangüíneo na oitava hora foram mais altos nos animais medicados com bicarbonato e lactato-L que nos animais dos demais tratamentos, enquanto que na quarta hora esses valores foram mais altos nos medicados com cloreto e lactatoLD $(\mathrm{P}<0,05)$. Não houve diferenças entre as pressões de $\mathrm{CO}_{2}$ dentro dos tratamentos com bicarbonato, cloreto, lactato $\mathrm{DL}$ e acetato $(\mathrm{P}<0,05)$, porém maiores valores foram obtidos na quarta e oitava horas em relação à primeira hora para o lactato-L. $\mathrm{O} \mathrm{CV}_{\mathrm{b}}$ da pressão de $\mathrm{CO}_{2}$ foi $7,4 \%$.

A infusão de bicarbonato aumentou o $\mathrm{pH}$ urinário na primeira e oitava horas $(\mathrm{P}<0,05)$ (Fig.5). Dentre os vários tratamentos não houve diferenças entre os tempos de análise, excetuando-se o cloreto, em que o pH urinário foi mais alto na primeira hora em relação aos demais tempos $(\mathrm{P}<0,05)$. $\mathrm{O} \mathrm{CV}_{\mathrm{b}}$ do $\mathrm{pH}$ urinário foi $6,5 \%$.

\section{DISCUSSÃO}

Os resultados indicaram que é possível a utilização de tampões metabolizáveis, alternativos ao bicarbonato, para a elevação do $\mathrm{pH}$ sangüíneo em bovinos sadios, com vista à correção de um estado de acidemia.

É sensato e evidente dizer que o aumento do $\mathrm{pH}$ sangüíneo após a infusão da solução de bicarbonato ocorreu devido à maior concentração dessa substância nesse fluido. A elevação do $\mathrm{pH}$ também foi constatada, em diferentes graus, com o uso dos tampões metabolizáveis. Credita-se esse aumento muito mais aos eventos oxidativos desses tampões, em cujo processo há consumo de íons $\mathrm{H}^{+}$, que à geração propriamente dita de bicarbonato, o qual aumenta seu teor no sangue devido ao seu menor uso para tamponar eventuais estados de acidemia na corrente sangüínea (Naylor e Forsyth, 1986). Assim, verificou-se, já na primeira hora, aumento nos teores de bicarbonato sangüíneo após a infusão de propionato e na quarta e oitava horas após o uso de lactato-L (Fig. 2). 


\section{Leal et al.}

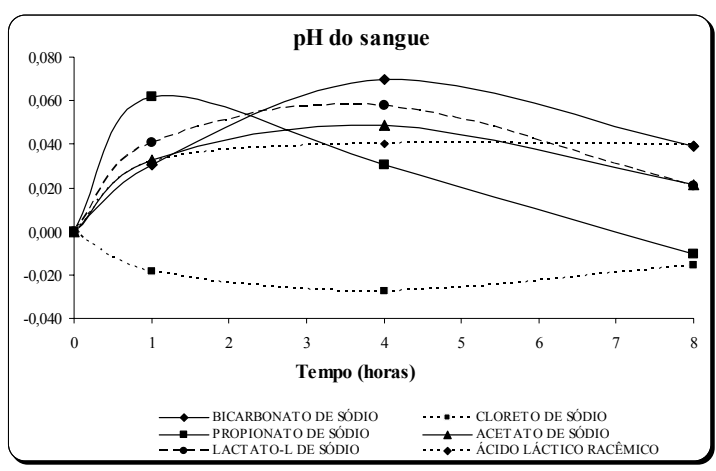

Figura1. Valores médios do $\mathrm{pH}$ sangüíneo de bovinos infundidos nos momentos $0,1,4$ e 8 horas com seis diferentes soluções.

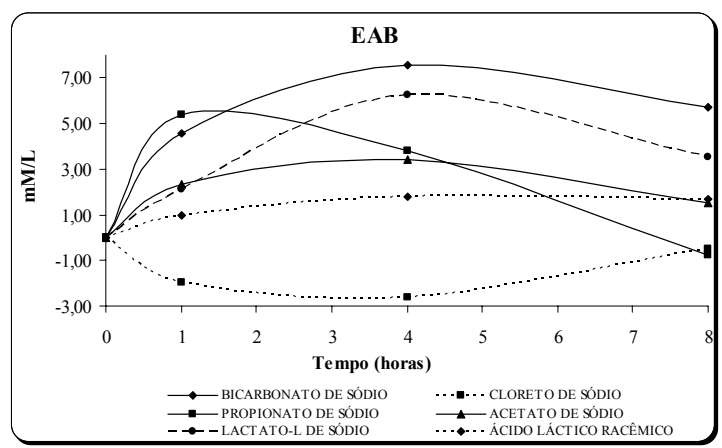

Figura 3. Valores médios da concentração de excesso ácido-base sangüíneo (EAB - $\mathrm{mMol} / \mathrm{l})$ de bovinos infundidos nos momentos $0,1,4$ e 8 horas com seis diferentes soluções.

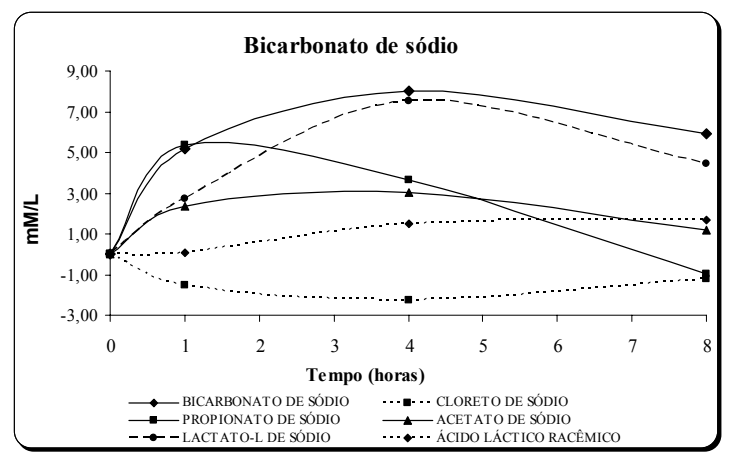

Figura 2. Valores médios da concentração de bicarbonato sangüíneo $(\mathrm{mM} / \mathrm{l})$ de bovinos infundidos nos momentos $0,1,4$ e 8 horas com seis diferentes soluções.

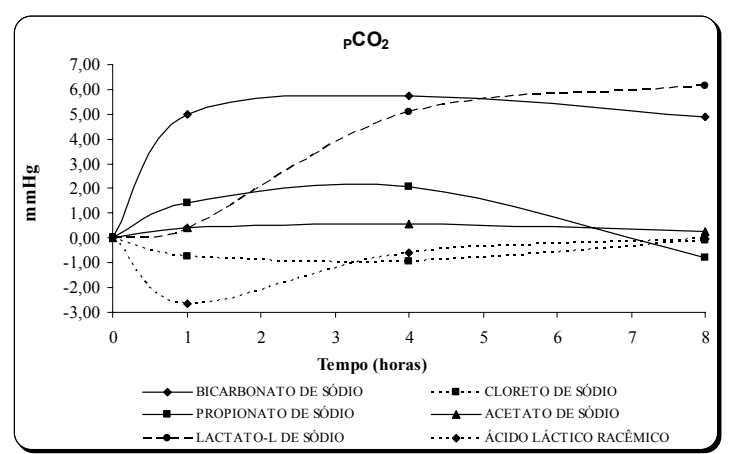

Figura 4. Valores médios da pressão de $\mathrm{CO}_{2}$ sangüíneo $(\mathrm{mmHg})$ de bovinos infundidos nos momentos $0,1,4$ e 8 horas com seis diferentes soluções.

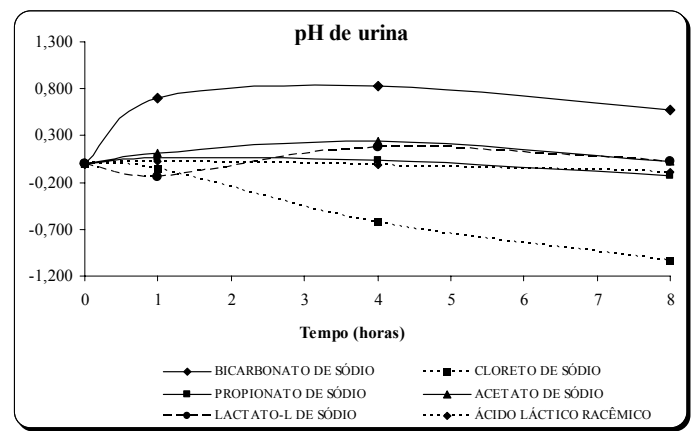

Figura 5. Valores médios no $\mathrm{pH}$ de urina de bovinos infundidos nos momentos $0,1,4$ e 8 horas com seis diferentes soluções.

Embora o tratamento com solução de bicarbonato tenha provocado significativo aumento da concentração de EAB prontamente na primeira hora pós-infusão, deve ter ocorrido, ao mesmo tempo, grande excreção desse composto na urina, já que o $\mathrm{pH}$ urinário se elevou destacadamente nesse momento (Fig. 5). Este fato indica que, diante de uma saturação de bases no sangue, o organismo sadio é capaz de excretá-las prevenindo-se contra a formação de um provável estado de alcalemia. Contudo, indica também que parte do bicarbonato infundido, em especial em animais sadios e possivelmente quando injetado rapidamente em bovinos acidóticos, pode ter sido perdida pela urina, já que estados de alta bicarbonatemia aumentam a excreção glomerular e diminuem a reabsorção tubular dessa substância (Ortolani, 2003). Esse maior $\mathrm{pH}$ urinário sugere, ainda, que, caso uma solução de bicarbonato seja 
injetada em grande quantidade em animais com insuficiência renal ou haja menor fluxo sangüíneo renal, por exemplo, numa desidratação severa, poderá haver o surgimento de grave quadro de alcalose metabólica. $\mathrm{O} \mathrm{pH}$ urinário foi pouco ou nada alterado após a infusão dos vários tampões metabolizáveis, indicando melhor aproveitamento das bases para elevação do $\mathrm{pH}$ sangüíneo.

Os resultados indicam que o lactato- $\mathrm{L}$ e, em menor grau, o propionato e o acetato foram os tampões metabolizáveis que mais produziram aumentos significativos no $\mathrm{pH}$ sangüíneo e na concentração de EAB no decorrer do tratamento. O propionato elevou subitamente essas variáveis durante a primeira hora de tratamento e posterior diminuição de forma progressiva, mostrando que a ação alcalinizante foi temporária e fugaz. Um estudo anterior testou o efeito da administração oral de relativamente altas doses de propionato (343g) sobre o $\mathrm{pH}$ sangüíneo de vacas, e verificou que o tampão elevou, de maneira significativa, essa variável, a partir de $30 \mathrm{~min}$ até a sexta hora pós-administração, no decorrer do experimento (Bigner et al., 1997). Contudo, a quantidade total de propionato utilizada pela via oral foi mais de seis vezes maior que a empregada neste trabalho $(54,75 \mathrm{~g})$. Doses muito altas de propionato podem provocar hiperglicemia, que, por sua vez, causa parada ruminal temporária, sendo assim um efeito colateral indesejável (Kronfeld, 1972).

Constatou-se, ainda, que o tratamento com tampões metabolizáveis também promoveu o aumento das reservas de tampões no organismo, verificado pela elevação das concentrações de bicarbonato e EAB sangüíneos. Apesar de o acetato, lactato-LD e em menor grau o propionato promoverem aumento significativo no $\mathrm{pH}$ sangüíneo, esses mesmos compostos não conseguiram aumentar as reservas de tampões orgânicos, na mesma magnitude que o lactato- $\mathrm{L}$ e o bicarbonato, ao término dos tratamentos, na quarta hora de infusão. Dessa forma, constatouse que em bovinos adultos sadios apenas $o$ lactato-L, entre os tampões metabolizáveis estudados, apresentou capacidade de tamponamento semelhante à do bicarbonato. Este resultado diferencia-se dos obtidos por Naylor e Forsyth (1986) que detectaram, em bezerros sadios recém-nascidos, maior capacidade alcalinizante do acetato que o lactato-L, pela mais rápida oxidação do primeiro composto. Numa revisão sobre o metabolismo de ácidos graxos voláteis e lactato em ruminantes, Armentano (1992) evidenciou que o lactato-L é muito mais rapidamente oxidado que o acetato, o qual é convertido em outros compostos tais como ácidos graxos de cadeia longa e gordura. Segundo Naylor e Forsyth (1986), o acetato só consome íons $\mathrm{H}^{+}$quando o composto é oxidado, o que provavelmente ocorre com maior intensidade em bezerros que em bovinos adultos.

Embora a infusão racêmica de lactato-LD tenha promovido, no decorrer do experimento, semelhante aumento no $\mathrm{pH}$ sangüíneo em relação ao lactato-L, a forma racêmica não conseguiu, efetivamente, aumentar as reservas de tampões do organismo, tanto de bicarbonato como de EAB sangüíneos, não produzindo efeito prático na correção da acidose. Assim, um eficiente tampão no animal sadio deve promover um quadro leve de alcalose metabólica. Quando essa alcalose acontece, o organismo compensa com retenção sangüínea de $\mathrm{CO}_{2}$, a fim de equilibrar o desvio no equilíbrio ácido-básico (Kaneko et al., 1997). $\mathrm{Na}$ análise da $\mathrm{pCO}_{2}$ realmente ficou constatado que essa pressão foi maior no lactato$\mathrm{L}$ que no LD. Vários estudos anteriores demonstraram que o fígado consegue metabolizar o lactato em piruvato com muito maior eficiência ao utilizar a forma $\mathrm{L}$ que a $\mathrm{D}$, devido à maior atividade da enzima L-lactato desidrogenase que a correspondente ao seu outro isômero (Dunlop, 1972). Assim, os menores efeitos alcalinizantes do lactato racêmico estão ligados à menor quantidade do isômero L na solução, já que no tratamento lactato-L a quantidade dessa substância foi o dobro da solução LD. Merecem destaque os altos valores de $\mathrm{pCO}_{2}$ encontrados ao término do experimento nos animais infundidos com bicarbonato $\mathrm{e}$ lactato-L, indicando que essas substâncias promoveram contínua e expressiva alcalinização. Por sinal, apenas esses dois tratamentos geraram, em alguns animais, na quarta hora, valores de $\mathrm{pH}$ sangüíneo acima de 7,40, limite superior da referência de normalidade em bovinos aqui criados (Ortolani, 2003).

\section{CONCLUSÕES}

As soluções de bicarbonato e lactato-L foram as que promoveram maior capacidade alcalinizante 
em bovinos sadios, entre os tampões estudados. A ligeira alcalose metabólica gerada pela infusão de bicarbonato e lactato- $\mathrm{L}$ provocou resposta compensatória com retenção de $\mathrm{CO}_{2}$ sangüínea.

\section{AGRADECIMENTOS}

Os autores agradecem ao CNPq pelo auxílio financeiro para execução desta pesquisa e a bolsa de aperfeiçoamento concedida à primeira autora. Também é meritório o reconhecimento do apoio técnico da laboratorista Regina Mieko Sakata Mirandola e ao Dr. Celso Akio Maruta.

\section{REFERÊNCIAS BIBLIOGRÁFICAS}

ARMENTANO, L.E. Ruminant hepatic metabolism of volatile fatty acids, lactate and pyruvate. J. Nutr., v.122, p.838-842, 1992.

BIGNER, D.R.; GOFF, J.P.; FAUST, M.A. et al. Comparison of oral compounds for the correction of acidosis. J. Dairy. Sci., v.80, p. 2162-2166, 1997.

DUNLOP, R.H. Pathogenesis of ruminant lactic acidosis. Adv. Vet. Sci. Com. Med., v.16, p. 259302, 1972.

HARTSFIELD, S.M.; THURMON, J.C.; BENECH, G.J. Sodium bicarbonate and bicarbonate precursors for treatment of metabolic acidosis. J. Am. Vet. Med. Assoc., v. 179, p.914916, 1981.
KANEKO, J.J.; HARVEY, J.W., BUSS, M.L. Clinical biochesmistry of domestic animals. 5.ed. San Diego: Academic, 1997. 932p.

KRONFELD, D.S. Ketosis in pregnant sheep and lactating cows. A review. Aust. Vet. J., v.48, p. 680-687, 1972.

MARUTA, C.A.; ORTOLANI, E.L. Suscetibilidade de bovinos das raças Jersey e Gir à acidose láctica ruminal: Acidose metabólica e metabolização do lactato-L. Cien. Rural, v.32, p.61-65, 2002.

NAYLOR, J.M.; FORSYTH, G.W. The alkalinizing effects of metabolizable bases in the healthy calf. Can. J. Vet. Res., v.50, p.509-516, 1986.

ORTOLANI, E.L. Diagnóstico e tratamento de alterações ácido-básicas em ruminantes. In: SIMPÓSIO DE PATOLOGIA CLÍNICA VETERINÁRIA., 2003, Porto Alegre. Anais. Porto Alegre, 2003. v.1, p.17-28.

RADOSTITIS, O.M.; GAY, C.C.; BLOOD, D.C. et al. Clínica veterinária. Um tratado de doenças dos bovinos, ovinos, suínos, caprinos e eqüinos. 9.ed. Rio de Janeiro: Guanabara Koogan, 2002. $1737 \mathrm{p}$.

SAMPAIO, I.B.M. Estatística aplicada à experimentação animal. 2.ed. Belo Horizonte: FEP-MVZ, 2002. 265p.

SUCUPIRA, M.C.A.; ORTOLANI, E.L. Uso do sangue arterial e venoso no exame do equilíbrio ácido-básico de novilhos normais ou com acidose metabólica. Cien. Rural., v.33, p.863868, 2003. 